\title{
Fuzzy Expert System for Selecting and Recruiting Personnel
}

\author{
Quashie Duodu \\ Department of Mathematics/ICT \\ Ada College of Education, Ada
}

\author{
Seidu Kwame Hamidu \\ Department of Mathematics/ICT \\ Ada College of Education, Ada
}

\begin{abstract}
Selection and recruitment is a critical decision-making in anyorganization. The main aim of this researchwas to develop a multi-portfolio Fuzzy Logic Expert System to aid in recruitment and selection of personnel in an establishment. Case-study was conducted in Kings University College, a private university in Ghana. Fuzzy logicalgorithm and flowchart of the algorithm was developed. The algorithm was simulated using MATLAB 7.8.0 (R2009a).Using Chief Security Portfolio, the system was used for selecting a personnel. Fuzzy logic offered accurate and simplified way of recruiting personnelof out of 16 randomly sampled applicant at Kings University College.
\end{abstract}

\section{Keywords}

Fuzzy variable, linguistic variable, fuzzy decision matrices

\section{INTRODUCTION}

Recruiting a rightful person to fill vacancy in an establishment is a crucial decision process. This is because the person employed undertakes the combination of other factors in the organization to achieve the possible best result.As a result, it is not prudent to allow a person or persons to saddle with due to human shortfall factors such as mood fluctuation,favoritism andinconsistency. Personnel selection process and quality of employeesare the engine of every institution, and hence, have always been an important topic for organizations [1]. Much as there is a need for a system to help in the selection of an idea person, there is a need to consider accuracy and simplicity. Again, many researchers have worked on using fuzzy systems as a tool to aid in selecting candidates, they have failed to distinguishthe selection criteria of one portfolio to the other. For instance, the requirement for selecting a manager is different from that of a security personnel in a criteria like qualification. Thus making their systems tailored to a specific portfolio recruitment. In this paper, Fuzzy Logic Recruitment Expert System is proposed for a multi-portfolio selection.

\section{LITERATURE REVIEW}

No organization in existence is free from recruitment and placement problems. In dealing with this problem, one group employed ranking and fuzzy logic. They noticed, mathematical models quantify magnitudes that are not always objective hence fuzzy set theory was developed and used. They concluded that fuzzy logic models fit more accurately to managers' thinking when implementing human resources policies [2]. In other research, fuzzy TOPSIS was used as the analytical tool to determine weight of each criterion in personnel selection but ended up that fuzzy theory provides a proper tool to encounter with uncertainties and complex environment [3]. In a conclusion remark by researchers, fuzzy methodology embedded in a fuzzy software tool developed in the Java programming language, observed that their technique can offer significantly opportunities and chances to achieve the excellence in personnel selection [4].Others observed that fuzzy method of selection, hamming distance and a Matching Level Index make it possible for candidates to be ranked even when the competences of the ideal candidate have been evaluated only in part [5]. Other researchers believed that interdependencies of factors of personnel selection should be considered [6]. Others noted thatfuzzy expert system is capable for evaluating personnel capabilities [7]. Another researchers opine that two-phase multiple criteria stochastic dynamic programing approach using analytic hierarchy process (AHP) and dynamic programming (DP) should be used for personnel selection [8].Carefully choosingweights for skills and tasks in advance of evaluation of applications, the fuzzy methodachieves a rational basis for assessment [9].Conclusively, others believe fuzzy Logic Model leads to thorough capacity assessment of personnel [10]. Another group of researchers attempted solving the problem of personnel selection by using PROMETHEE, Fuzzy Logic and Weighted Average [11].It can be noted that many researchers blend fuzzy logic with other techniques in solving the problem of personnel selection making their systems complex. In this paper, only fuzzy logic is used to address personnel selection problems.

\section{METHODOLOGY}

\subsection{Data Collection}

This research is a case study conducted at Kings University College in Ghana with staff and student population of 1093 . Purposive sampling of 9 human resource experts were selected and used to capture the knowledge base of the system using data collection instruments like questionnaire, interview and consultation. Fuzzy variables, linguistic variables and fuzzy decision matrices were designed. Algorithm and flowchart of the algorithm was developed. The algorithm was simulated using MATLAB 7.8.0 (R2009a)

\subsection{Model of the Existing Personnel Selection}

The fig 1 below shows how an existing model is used by human resource managers recruit and place personnel in the organization.s 


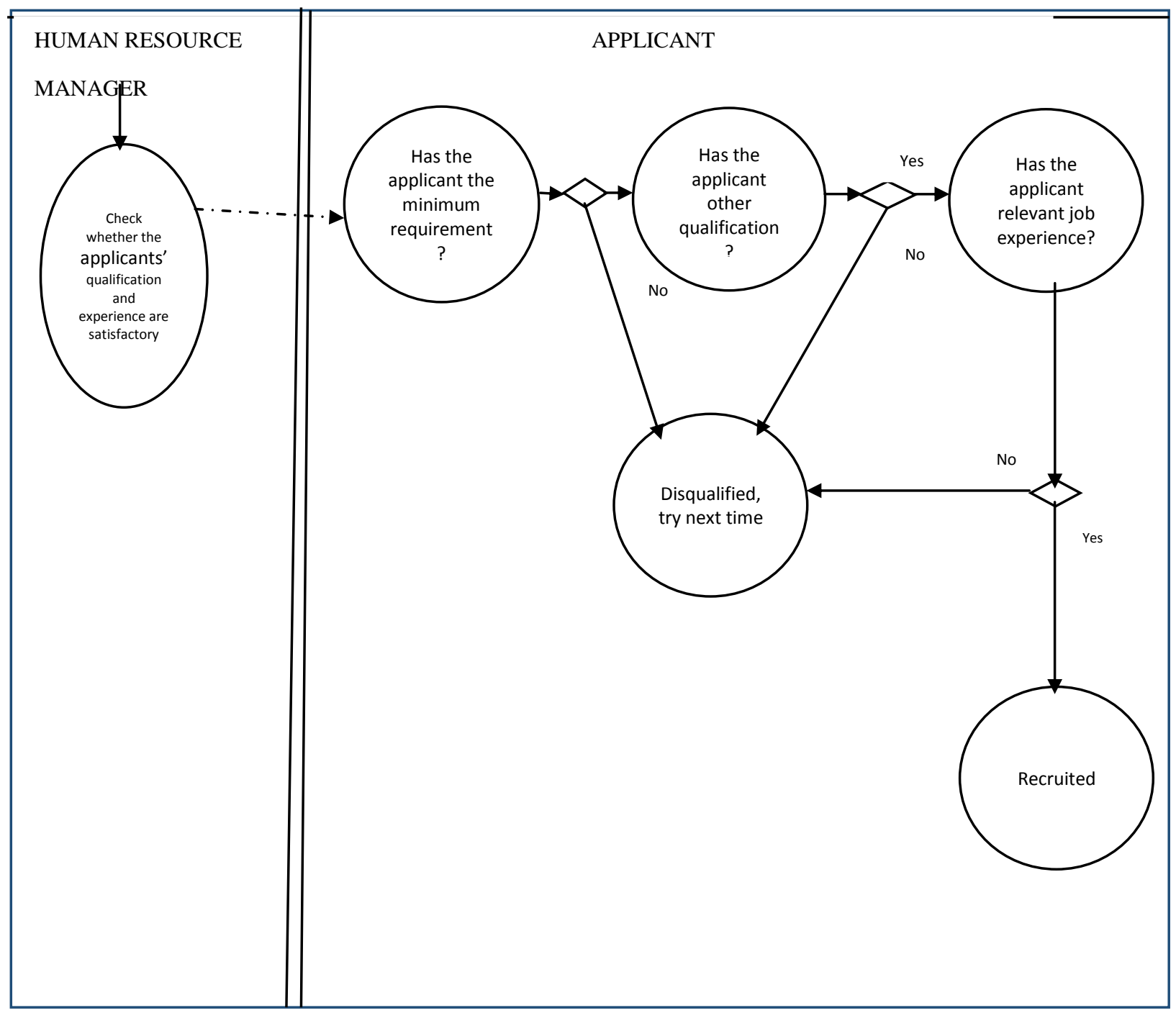

Fig 1: Model of the existing personnel selection

\subsection{Model of the Designed System'}

\section{Personnel Selection}

The fig 2 below shows how the designed Fuzzy Logic Recruitment Expert System is used to recruit and place personnel in the organization. 


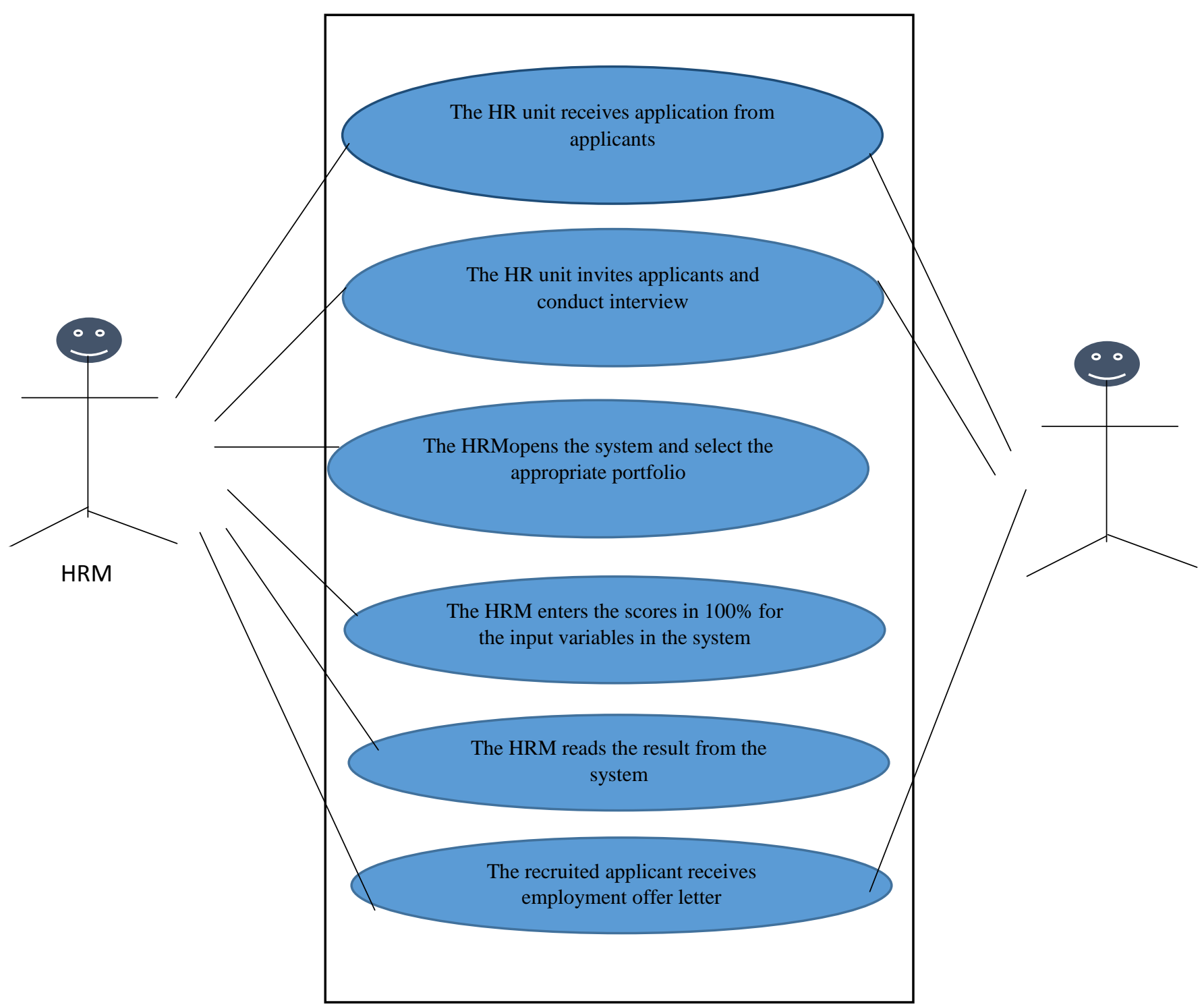

Fig 2: Model of the designed systems' selection

\section{IMPLEMENTATION}

\subsection{Structure of the ExpertSystem}

The fig 3 below shows the architecture of the Fuzzy Logic Recruitment Expert System. The main components of the system are fuzzification, knowledge base, inference engine, and defuzzification.

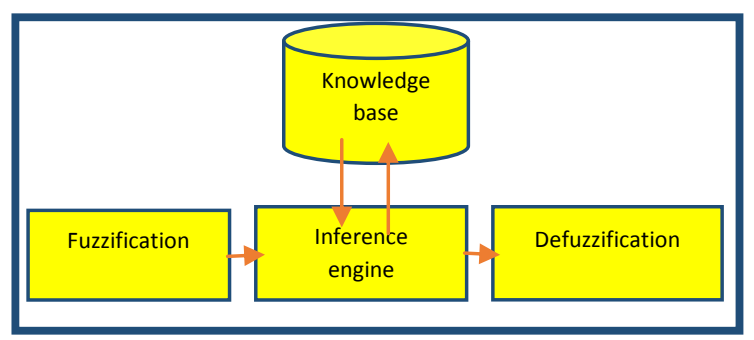

Fig 3: Architecture of the Fuzzy Recruitment System

\subsubsection{Fuzzification}

The crisp input entered is mapped to its linguistic variable using membership function of each fuzzy variable. Nine fuzzy variables namely qualification, relevance experience, experience duration, interview score, age, computer skills, foreign language, communication skills, driving licensewere used with each variable having four linguistic variables, namely low, moderate, high, excellent. Fig4, and fig5 show triangular membership function plots of qualification, and relevance experience of mechanic portfolio from MATLAB 7.8.0

\subsubsection{KnowledgeBase}

The Knowledge base is where the captured human expert is store for reference by the inference engine. The fuzzy decision matrices uses forward chaining and logical AND operator.

\subsubsection{Inference Engine}

Inference engine matches the fuzzified inputs with the fuzzy decision matrices in the knowledge base to provide an output. Samples of the fuzzy decision matrices of Mechanic portfolio are shown below:

T1: if min(qualification(low), R_experience(Low), D_experience(low), interview(low), computer(low), age(low), F_language(low), D_license(low) then Recruitment_Info = "Rejected" and Placement_Info = "No placement") 
T2: if min(qualification(excellent),

R_experience(excellent),D_experience(high),

interview(excellent), age(excellent), F_language(excellent), com_skills(excellent),D_lincese(excellent)then

Recruitment_Info="Recruited" and Placement_Infor =

"Placedin the office")

\subsubsection{Defuzzification}

Here, crisp output is produced from the Fuzzy Logic Recruitment Expert System.

\subsection{The Algorithm}

The algorithm of the Fuzzy Logic Recruitment Expert system is as follows:
1. Start
2. Select the specific portfolio
3. Read the input data of the fuzzy variables;
4. Evaluate the variables against the fuzzy inference system;
a. Construct membership function of each input variable;
b. Match the function of the variables with the fuzzy decision matrix in the $\mathrm{KB}$;
c. Determine whether the applicant qualifies;

5. If the applicant qualified, then Else

a. Display recruit and place the applicant;

6. Stop

b. Display "Rejected or pending";

\subsection{Flowchart of the Algorithm}

The flowchart of the fuzzy logic algorithm is shown in fig 6

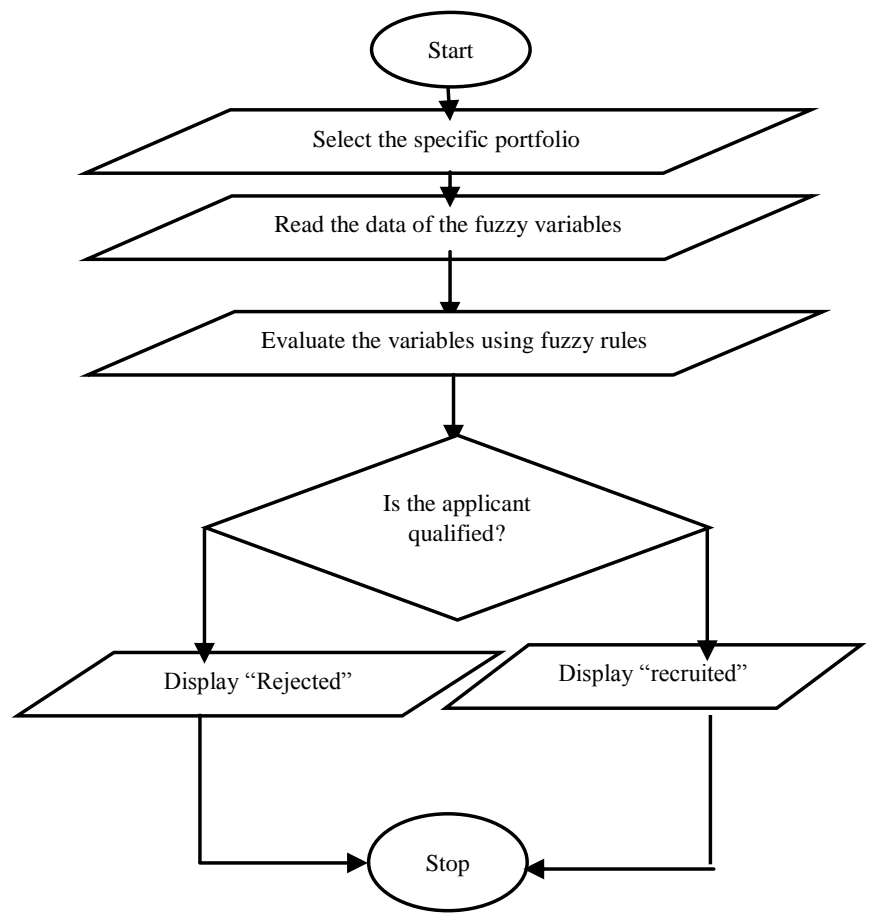

Fig 6: Flowchart of the fuzzy algorithm

\subsection{Simulation of the Algorithm}

The algorithm was simulated using Fuzzy Logic toolbox in MATLAB 7.8.0 (R2009a). The FIS Editor of the Fuzzy Logic Recruitment Expert System of Chief Security portfolio is shown in fig 7

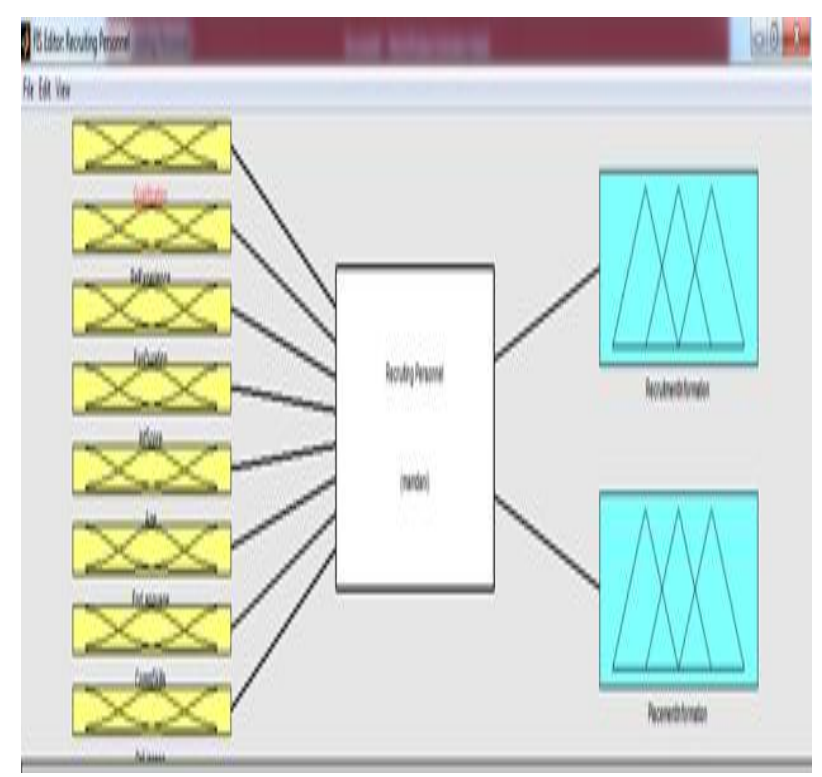

\subsection{Experimentation and Result}

Running test of the designed system was conducted for 4 different portfolio, namely Office Secretary, Dispatch Officer, Motor Mechanic, and Chief Security. Table 1 shows results obtained in Chief Security.

Table 1: Result of the recruitment of Chief security portfolio

\begin{tabular}{|c|c|c|}
\hline \multirow{2}{*}{ Applicant's ID } & \multicolumn{2}{|c|}{ Mechanic portfolio } \\
\cline { 2 - 3 } & Result & $\begin{array}{c}\text { Intensity } \\
\mathbf{( 1 0 0 \% )}\end{array}$ \\
\hline $001-03-02-2014$ & Rejected & 45 \\
\hline $002-03-02-2014$ & Rejected & 41 \\
\hline $003-03-02-2014$ & Rejected & 48 \\
\hline $004-03-02-2014$ & Rejected & 54 \\
\hline $005-03-02-2014$ & Pending & 63 \\
\hline $006-04-02-2014$ & Rejected & 55 \\
\hline $007-04-02-2014$ & Rejected & 49 \\
\hline $008-05-02-2014$ & Pending & 67 \\
\hline $009-05-02-2014$ & Rejected & 41 \\
\hline $010-05-02-2014$ & Rejected & 54 \\
\hline $011-05-02-2014$ & Recruited & 89 \\
\hline $012-05-02-2014$ & Rejected & 47 \\
\hline $013-06-02-2014$ & Rejected & 33 \\
\hline $014-06-02-2014$ & Rejected & 51 \\
\hline $015-07-02-2014$ & Rejected & 42 \\
\hline $016-07-02-2014$ & Rejected & 55 \\
\hline
\end{tabular}

From table 1 above, applicant with ID 0010-05-02-2014 is recruited with intensity mark of 89 . 0007-05-02-2014 and 0004-03-02-2014 are asked to be on standby for the office in case 0010-05-02-2014 fails to take up the employment offer. The rest of the applicants are rejected.

\subsection{Conclusion}

Recruitment and placement Fuzzy Logic System was developed and used. Fuzzy logic offer accurate and simplified way of recruiting personnel.

\subsection{Area for further studies}

It will not be possible to use the system for the selection of personnel for different organization because job requirement 
specificationsare specific or different from organization to another organization.

\section{REFERENCES}

[1] Afshari, A., Mojahed, M. and Rosnah, M. Y. 2010. Simple Additive Weighting approach to Personnel Selection Problem. International Journal of Innovation, Management and Technology, Vol. 1, No. 5, December 2010 ISSN: 2010-0248

[2] Fuller, R and Lourdes, C. D.Transparent Fuzzy Logic Based Methods for Some HumanResourcesproblems RevistaElectrónica de Comunicaciones y Trabajos de ASEPUMA. Volumen 13. Paginas 27 a 41 .

[3] Matin, Z. H., Fathi, R. M., Zarchi, K. M., Azizollahi, S. 2011, The Application of Fuzzy TOPSISApproach to Personnel Selection for Padir Company, Iran, Journal of Management Research, ISSN 1941-899X, Vol. 3, No. 2: E15

[4] Sîrb, L. and Dragolea, L. A. 2013. Qualitative Approach in Terms of Fuzzy Logic Related to the Excellence Achieving Within Managerial Process of Personnel Selection, Polish Journal of Management Studies, Sîrb L. Dragolea L., vol.7

[5] Lourdes, C., Trinidad, C., Enric, C., Tomas L., Juan C. P. 2011. Personnel Selection Based on Fuzzy Methods. Revista de Matem'atica: Teor'1a y Aplicaciones.18(1): 177-192 cimpa - ucrissn: 1409-2433
[6] Dagdeviren, M. and Yuksel, I. 2007. Personnel SelectionUsing Analytic Network Process", İstanbul Ticaret Üniversitesi Fen Bilimleri DergisiYıl: 6 Sayı: 11 Bahar 2007/1 s. 99-118

[7] Luis, D. O. 2009. A framework for resource assignments in skill based environments", University of South Florida, Scholar Commons, These and dissertations, 6-12009

[8] Asli, O. 2013. A two-phase multi criteria dynamic programing approach for personnel selection process ", Problems and Perspectives in Management, Volume 11, Issue 2.

[9] Misha, L., Sonja, P. L. and Bruce, B. 1999. A Fuzzy Approach toPersonnel Selection", Monash University Faculty of Business and Economics, Working Paper 44/99

[10] Luis, D. O.and Carlos, E. O. 2012. A fuzzy expert system architecture for capability assessments in skill-based environments", Expert Systems with Applications 39, 654-662.

[11] Turkay, D.,Alptekin, D., Serap, U. S. and Nevra, A. 2010. A fuzzy approach for personnel selection process, TJFS: Turkish Journal of Fuzzy Systems (eISSN: 13091190) An Official Journal of Turkish Fuzzy Systems Association Vol.1, No.2, pp. 126-140, 2010. 